\title{
The new Principles on Effective Intervie- wing for Investigations and Information Gathering - An overview
}

\author{
Barbara Bernath'
}

'In my time as Special Rapporteur on Torture, I observed that the most frequent setting where torture and coercion takes place is the course of interrogation of suspects and for the purpose of obtaining confessions or declarations against others', states Juan E. Méndez in his foreword to the new Principles on Effective Interviewing for Investigations and Information Gathering. ${ }^{2}$

The Principles (also known as 'Méndez Principles'), which were launched in June 2021 , are now available in several languages. ${ }^{3}$ This article looks at the main innovative features of the Principles and present an overview of their content.

\section{A solution oriented tool to shift mindset from coercive interrogation to rapport- based interviewing}

The development of the Méndez Principles was an expert driven process that was initiated in January 2017 following a strategic meeting with a variety of stakeholders in Geneva. The

1) Secretary General of the Association for the Prevention of Torture

2 Principles on Effective Interviewing for Investigations and Information Gathering, May 2021. Retrieved from www.interviewingprinciples.com (hereinafter "Principles").

3 See Association for the Prevention of Torture (APT), at https:/www.apt.ch/en/what-we-do/campaigns/ principles-effective-interviewing . process was supported by the Association for the Prevention of Torture (APT), the AntiTorture Initiative (ATI) and the Norwegian Center for Human Rights (NCHR), and led by a Steering committee of 15 experts from different regions and fields of expertise. A large Advisory Council of more than 80 persons from over 40 countries also contributed to the drafting process. Enriched by three national roundtables (in Brazil, Tunisia and Thailand) ${ }^{4}$ and two consultations with the Advisory Council in 2020, the final text is structured around six core principles. The Principles were finalized in May 2021 and officially launched on 9 June $2021 .^{5}$

The Principles are centered around the core idea that the purpose of interviewing is to obtain accurate and reliable information in order to elicit the truth about matters under

4 See APT, International Standards on Non-Coercive Interviewing and Associated Safeguards: One Step Closer to Completion of Guidelines, 20 September 2019, at https://www.apt.ch/en/news on_prevention/international-standards-non-coerciveinterviewing-and-associated-safeguards-one; and APT, Good progress towards "Universal Protocol on Investigative Interviewing and Associated Safeguards", 11 December 2018, at https://www.apt ch/en/news_on_prevention/good-progress-towardsuniversal-protocol-investigative-interviewing-and

5 The video recording of the launching event is available at https://vimeo.com/561236604 
investigation ${ }^{6}$. They provide a broad and innovative framework of reference for decision makers for reforming interrogation practices with a view to contributing to more professional policing and better outcomes of investigations and information gathering, while at the same time respecting human rights.

"The primary innovation is to present normative guidance for what police should do in effective and ethical investigations, rather than simply restating the absolute prohibitions against torture and ill-treatment" ${ }^{7}$ Indeed, the Principles propose an alternative to coercive practices that will help improve effectiveness, fairness and outcomes of investigation and intelligence gathering processes. This will be in the benefit not only of the interviewee's dignity and rights, but also of the interviewer who can achieve better investigation results, and ultimately serve justice for the society altogether.

This constructive approach is the result of a multidisciplinary drafting process. Experts from the Steering Committee not only came from different professional backgrounds but also with different experience and expectations of what was needed to move away from coercive practices and overreliance on confessions. The combined expertise and approaches of police practitioners, intelligence experts, psychologists, academics and human rights defenders result in a document that uniquely

6 See also Human Rights Council resolution on 'Torture and other cruel, inhuman or degrading treatment or punishment: the roles and responsibilities of police and other law enforcement officials' UN Doc. HRC/RES/46/15 adopted on 23 March 2021.

7 Rebecca Schaeffer, "The Mendez Principles: The Case for US Legislation on Law Enforcement Interview", 29 June 2021, Just Security blog series, at https://www.justsecurity.org/77244/the-mendezprinciples-the-case-for-us-legislation-on-lawenforcement-interviews/. combine interviewing techniques with human rights standards. This reflects the premise that "interviewing is complex adaptive process involving human beings, human behaviours and human rights". 8

The second innovative aspect of the Principles relates to the broad approach taken with respect to interviewing. Indeed, the Principles are not based on an existing model of investigative interviewing methodology. The objective of interviewing is to gather reliable and accurate information, not to get a confession. Interviewing is therefore understood as a structured conversation where one person ('the interviewer') seeks to gather information from another person ('the interviewee') as part of any investigation or intelligence operation. ${ }^{9}$ Accordingly, the Principles are applicable to a broad range of situations and actors. They apply to all type of interviews by information-gathering officials, such as police, intelligence, military, administrative authorities, or others acting in an official capacity. The Principles address primarily interviews with suspects during criminal justice investigations, but also apply to interviews with witnesses, victims or any other persons of interest. While the Principles reckon that the applicability of some safeguards may differ depending on the legal status of the interviewee or in specific situations such as armed conflict, they conclude that "nevertheless, the conduct of interviews should always be guided by these Principles". ${ }^{10}$ Further, the Principles are applicable to all justice systems, legal traditions and cultures, regardless of the national legislation, policies and procedures. $\begin{array}{ll}8 & \text { Principles, para } 55 . \\ 9 & \text { Principles, para } 2 . \\ 10 & \text { Principles, para } 13 .\end{array}$ 
Principle 1: Effective interviewing is instructed by science, law and ethics.

\section{The Principles are evidence-based}

The multidisciplinary approach of the drafting process results in a document that uniquely integrates science, law and ethics throughout. Arguably, the fight against torture is still largely dominated by lawyers and there is a certain reticence to base arguments on science. However, this is changing, as "experts in law, ethics, and science increasingly understand that these disciplines reinforce each other and can be integrated". ${ }^{11}$ Reflecting this trend, the strength of the Principles lies on its strong foundations in scientific and empirical research combined with latest legal and ethical standards, thereby providing a strong evidence-based response to any utilitarianism approach trying to justify torture in the name of security or the fight against terrorism.

Principle 1 provides for a robust evidence-based research analysis showing first that coercive interrogation practices are ineffective and counterproductive in getting accurate and reliable information, and second that rapport based interviewing is effective in getting reliable and accurate information. Numerous studies from a wide range of disciplines, including psychology, criminology, sociology, neuroscience and medicine have proven that coercive methods lessen the propensity of the interviewee to cooperate, create resistance and

11 Steven J. Barela and Mark Fallon. "The Mendez Principles: Leadership to Transform Interrogation via Science, Law and Ethics", 1 June 2021, Just Security blog series, at https://www.justsecurity.org/76709/ the-mendez-principles-leadership-to-transforminterrogation-via-science-law-and-ethics/ . contaminate the memory. Research also shows that interviewers aiming at getting a confession are frequently influenced by "confirmation bias" and interpret information confirming their belief of guilt. Furthermore, when information is eventually provided, it is often unreliable and leads to false confession and possibly miscarriages of justice, even more so in the case of interviewees in situation of vulnerability. On the other hand, decades of research shows that rapport-based interviewing is effective in gathering criminal and intelligence information. This is achieved by establishing a relation -i.e. a connection - between the interviewer and the interviewee and using a set of proven effective interviewing techniques (see below Principle 2).

Along with science, the Principles are grounded in existing international human rights law and standards, in particular the absolute prohibition of torture and other ill-treatment, as well as the freedom from arbitrary arrest and the right to be free from discrimination. In addition, the right to remain silent and the presumption of innocence are at the core of the Principles. These foundational rights contribute together to ensure respect for the right to a fair trial, an essential element of the rule of law.

Last but not least, effective interviewing is governed by ethical standards enshrined in professional regulations such as codes of conduct. The Principles emphasize in particular the importance of respect, fairness and honesty as the foundations for all interviews and the ethical duty to adopt the most effective interviewing methods and to reject coercive tactics.

\section{The Principles uniquely combine interviewing techniques with the implementation of legal and procedural safeguards}

The Principles provide concrete guidance into the practice of interviewing before, during and after the interview, without however pro- 
Principe 2: Effective interviewing is a comprehensive process for gathering accurate and reliable information while implementing associated legal safeguards.

Principle 3: Effective Interviewing requires identifying and addressing the needs of interviews in situations of vulnerabilities.

posing a step-by-step manual. Importantly and uniquely, the Principles integrate legal and procedural safeguards throughout. Implementation of fundamental safeguards in practice are effective measures in reducing the risk of torture and ill-treatment. ${ }^{12}$ Further, as the European Committee for the Prevention of Torture noted, the investigative interviewing approach "dismantles the myth of the effectiveness of harsh interrogation methods (including ultimately torture) and replaces it with more effective methods of preventing, detecting, investigating and solving crimes". ${ }^{13}$

Interviewing is not a one off-event but is a process that starts from the first moment of encounter between the State authorities and a person until the release or presentation to a judge. This means that the respect for the dignity and human rights of the interviewee has to be guaranteed from the outset in order to create a non-coercive environment. Safeguards are key at the moment of arrest or apprehension, transfer and arrival in custody, when there is a high risk of torture and ill-treatment. Notification of a relative or a third party, access to a medical examination and health care, and access to a lawyer

12 Richard Carver and Lisa Handley, Does torture prevention work?, Liverpool University Press, 2016.

13 See European Committee for the Prevention of Torture and Inhuman or Degrading Treatment or Punishment (CPT), $28^{\text {th }}$ annual report of activities, 1 January 31 December 2018, CPT/INf(2019)9, April 2019, para 79, available at https://rm.coe. int/16809420e3. further contribute to more transparency and protection. ${ }^{14}$ Effective interviewing also requires thorough preparation by the interviewer and includes reviewing all existing evidence and information, defining the objective and the strategy as well as prepare how and when to use evidence.

Importantly, the Principles elaborate on interviewing skills and techniques enabling to establish and maintain rapport with the interviewee, such as providing information, active listening, use of open-ended questions, free flow of accounts that can be complemented with probing questions (who, what, where). These techniques will also help dealing with reluctant detainee. The presence of a lawyer during the interview as well as audio-visual recording are safeguards that protect the interviewee against abuse but also the interviewer in case of false accusation.

The Principles recognize that, due to the inherent power imbalance, any interview places the interviewer in a situation of vulnerability. Some persons are in situations of heightened vulnerability due to their age, sex, gender identity, nationality or ethnic origin, disability and these vulnerabilities need to be duly assessed and addressed by the interviewer before and during the interview. Children in particular need special protection, and the presence of a lawyer or of a specially trusted person is compulsory during the interview.

\section{The Principles put a strong emphasis on implementation}

From the beginning, the development of the Principles included a strong emphasis on

14 See also Human Rights Council resolution on "Torture and other cruel, inhuman or degrading treatment or punishment: safeguards to prevent torture during police custody and pretrial detention", UN Doc. HRC/ RES/31/31 adopted on 24 March 2016. 
Principle 4: Effective interviewing is a professional undertaking that requires specific training

Principle 5: Effective interviewing requires transparent and accountable institutions

Principle 6: The implementation of effective interviewing requires robust national measures

implementation, not only at the institutional level but also at the national level. Moving away from coercive interrogation towards rapport based interviewing is a comprehensive process that aims at a shift of mind-set. This cannot happen at the level of the interviewer only and requires to consider the broader context of the organisational culture as well as the role of other national actors.

The Principles look at training as one of the key implementation measure. Accordingly, they recommend that all personnel involved in conducting interviews should receive specific training on effective interviewing, of sufficient length. Interviewing should also be integrated in the curricula not only for initial training but also as part of continuous professional development. The Principles recommend practical training focusing both on the process (how to prepare and plan the interview, conduct an analysis of information gathered, assess the process) and on the skills (keeping an open mind, building and maintaining rapport or interacting with reluctant interviewees), possibly by using use scenario-based exercises.

However, training is necessary but not sufficient to produce change, and it needs to be complemented by other measures at the institutional level. Implementation also requires leadership to ensure transparent and accountable institutions. Accountability includes for example a review of existing practices and standard operating procedures in order to integrate respect for effective interviewing and safeguards in all internal rules, and codes of conduct and assessment. It also means that the institution is able to react in case of inappropriate behavior and that the duty to report torture and ill-treatment is both required and protected..$^{15}$ Transparency means that internal rules and procedures related to interviewing should be made public ${ }^{16}$ and that independent oversight bodies can monitor the implementation through unannounced visits. Last but not least, independent complaint mechanisms shall be accessible, prompt and victims of torture or other ill-treatment receive redress and reparations.

The Principles also look at the broader State structure and the role of the legislative and judiciary branches. The domestic legal framework is an essential prerequisite for reform and includes criminalization of torture, strong legal safeguards and exclusion of evidence obtained through torture or ill-treatment. In this regard, the role of the judiciary and prosecution is essential to ensure that only lawfully obtained evidence is admissible in court proceedings.

Finally, replacing coercive interrogation by rapport-based interviewing and the implantation of safeguards will also require that responsible for torture are brought to justice and that impunity is put to an end. ${ }^{17}$

\section{Concluding remarks}

In conclusion, by putting the objective of gathering accurate and reliable information at the heart of any interviewing process, the

15 Principles, para 181

16 Principles, para 171.

17 Implementing the exclusionary rule and fighting against impunity are also key recommendations from the joint publication by Fair Trials and OOSCE/ ODIHR on 'Eliminating Incentives for Torture in the OSCE Region: Baseline Study and Practical Guidance', 2020. 
Principles propose a constructive and effective guidance for all agencies involved in interviewing. This solution-oriented approach provides better results both in terms of investigation and decision-making based on intelligence or information gathering and in terms of respect for human rights. The Principles therefore represent a useful guidance to move away from coercive practices and confession driven systems in favour of effective interviewing.

The Principles are primarily directed towards decision makers in law enforcement or intelligence agencies and will assist in shifting institutional culture and mindset from confession to information. Other actors, such as civil society, medical and bar associations, national human rights institutions and national preventive mechanisms also have a role to play in this reform and in the implementation of the Principles. In a topical metaphor, if we may think of interrogational torture like a virus, the Méndez Principles act as a vaccine ${ }^{18}$, and accordingly they protect not only the interviewee or the interviewer, but also the society as a whole.

18 See intervention by Mark Fallon, launching event of the Principles on Effective Interviewing, 9 June 2021, recording available at https://vimeo.com/561236604 . 